\title{
Structural, Photoluminescence and Electron Density Distribution Analysis of Rutile Phase $\mathrm{TiO}_{2}$
}

\author{
D. Sivaganesh, S. Saravanakumar, V. Sivakumar, S. Sasikumar, R. Rajajeyaganthan
}

\begin{abstract}
In this work, the mixed anatase and rutile phases of commercial $\mathrm{TiO}_{2}$ sample was purchased and converted to single rutile phase by sintering at $1000^{\circ} \mathrm{C}$. Structural and spectroscopic analysis of the single phased rutile $\mathrm{TiO}_{2}$ were analyzed by $\mathrm{PXRD}$, SEM, EDS, PL analysis, respectively. Rietveld profile refinement technique was performed to fit the observed and calculated $P X R D$ profiles. Charge density distribution studies were used to determine the chemical bonding nature of Ti-O bond by maximum entropy method (MEM). From the MEM calculations, Ti-O bond exhibited covalent nature. PL measurements showed that the emission wavelength of rutile $\mathrm{TiO}_{2}$ at around $470 \mathrm{~nm}$ which may be due to band to band transitions of Ti and $O$ atoms.
\end{abstract}

Keywords: Powder X-ray diffraction, Rietveld method, scanning electron microscopy, Charge density distribution

\section{INTRODUCTION}

$\mathrm{N}$ anostructured materials have gained great importance in various technological and industrial applications [1,2]. Especially, transition metal oxides are essential member of inorganic family and have been utilized as photocatalyst [3], catalyst [4], sensor [5], energy storage devices [6], dyesensitized solar cells [7] and many more applications. In particular, titanium dioxide $\left(\mathrm{TiO}_{2}\right)$ is an significant semiconductor material which has magnetic, electrical conductivity, good optical, dielectric, luminescent properties and so forth $[8,9]$. The aforesaid interesting physicochemical properties make them a superior candidate in energy and environmental aspects. Generally, $\mathrm{TiO}_{2}$ have been occurred three different allotropic phases such as rutile, anatase and brookite [10]. Amongst, rutile phase have been considered as

Revised Manuscript Received on December 29, 2019.

* Correspondence Author

S. Saravanakumar*, Department of Physics, International Research Centre, Kalasalingam Academy of Research and Education, Krishnankoil 626126. Tamil Nadu, India. Email: saravanaphysics@gmail.com

D. Sivaganesh, Department of Physics, International Research Centre,Kalasalingam Academy of Research and Education, Krishnankoil 626126.Tamil Nadu, India. Email: ganesh.siva650@gmail.com

S. Sasikumar, Department of Physics, International Research Centre,Kalasalingam Academy of Research and Education, Krishnankoil 626126.Tamil Nadu, India. Email: sasikuhan@gmail.com

V. Sivakumar, Department of Physics, International Research Centre,Kalasalingam Academy of Research and Education, Krishnankoil 626126.Tamil Nadu, India. Email: sivakumarvairan@gmail.com

R. Rajajeyaganthan, Department of Chemistry, International Research Centre,Kalasalingam Academy of Research and Education, Krishnankoil 626126.Tamil Nadu, India. Email: rajajeyaganthan.r@klu.ac.in more stable one, however, other two phases were easily converted into rutile form while heating above $500^{\circ} \mathrm{C}$ [11].

Therefore, various researchers have made an attempt for the synthesis of rutile phase with improved physical and chemical properties through the development of well-defined morphology, crystal defects, band gap narrowing, oxygen vacancies and active surface area [12]. However, various synthesis methods have been reported for the design of rutile phase $\mathrm{TiO}_{2}$ including co-precipitation [13], chemical vapour deposition [14], ball milling [15], sonochemical [16], sol-gel [17], hydrothermal [18], solvothermal [19] and hydrolysis [20] techniques. Among them, solid state sintering process could provide simple, cost effective, easy to handle, time consuming and requires low cost equipment [21]. Interestingly, the resultant final products were in uniform in size, high crystallinity and superior morphology [22]. On the other hand, electronic structure of the material was closely related to their bonding nature of the specified system which plays an essential role on their electrocatalytic, photocatalytic and photoluminescent properties. There are less number of researches has been done on the chemical bonding investigation of rutile $\mathrm{TiO}_{2}$ with single phase. The maximum entropy method [23] is used to analyze the bonding feature of $\mathrm{TiO}_{2}$ material. Motivated from the above facts, we synthesized rutile phase $\mathrm{TiO}_{2}$ through simple solid state technique with the aid of commercial $\mathrm{TiO}_{2}$. The successful formation of rutile phase $\mathrm{TiO} 2$ was confirmed by powder X-ray diffraction (PXRD), scanning electron microscope (SEM), energy dispersive X-ray (EDX) and photolumiscence (PL) instrumentation techniques. For the first time, the structural and bonding nature of rutile phase $\mathrm{TiO} 2$ was investigated in detail.

\section{EXPERIMENTAL}

\section{A. Sample preparation}

The Titanium Oxide $\left(\mathrm{TiO}_{2}\right)$ as a mixed phase (Anatase $80 \%$ and Rutile $-20 \%$ ) was procured from Sigma - Aldrich (Titanium (IV) oxide - nanopowder) with purity $\geq 99.5 \%$ and particle size of $21 \mathrm{~nm}$. The as procured $\mathrm{TiO}_{2}$ was taken in the alumina crucible and sintered at different temperatures such as $800^{\circ} \mathrm{C}$ and $1000^{\circ} \mathrm{C}$ for $3 \mathrm{~h}$ using box type muffle furnace. The obtained samples were characterized by structural, morphological and optical techniques. 


\section{B. Sample characterization}

The $\mathrm{TiO}_{2}$ materials were analyzed by "Powder X-ray Diffractometer" with $\mathrm{CuK} \alpha(\lambda=1.54056-\AA)$ radiation in the range of $10^{\circ}$ to $100^{\circ}$ with the interval of 0.02 '. The microstructure and surface morphology of the samples was measured using "scanning electron microscopy". Energy Dispersive X-ray Spectrometer (EDAX APEX) was used to analyses purity of $\mathrm{TiO}_{2}$. Photoluminescence excitation and emission spectra were recorded using Spectrofluorometer with a $150 \mathrm{~W}$ xenon lamp is a source of excitation.

\section{RESULTS AND DISCUSSION}

\section{A. Structural analysis}

The crystallinity of the commercial $\mathrm{TiO}_{2}$ and sintered $\mathrm{TiO}_{2}$ materials were characterized by PXRD. The PXRD of commercial $\mathrm{TiO}_{2}$ demonstrated the presence of mingled anatase and rutile phases, in which the anatase phase was dominant. After sintering of $\mathrm{TiO}_{2}$ at $800^{\circ} \mathrm{C}$ for $3 \mathrm{~h}$, the percentage of anatase phase was slightly reduced while the rutile phase of $\mathrm{TiO}_{2}$ was enhanced. But on sintering the $\mathrm{TiO}_{2}$ at $1000^{\circ} \mathrm{C}$ for $3 \mathrm{~h}$, the anatase phase disappeared and pure rutile phase of $\mathrm{TiO}_{2}$ was obtained. Fig. 1 shows powder Xray profiles of the $\mathrm{TiO} 2$ samples with different phases, which revealed the phase transition between mixed phases to pure Rutile phase. The single rutile phased $\mathrm{TiO}_{2}$ was compared with the standard JCPDS data with PDF No. 89 - 4202 and confirmed. The crystallite size of rutile phase $\mathrm{TiO} 2$ was calculated using Scherer ${ }^{\text {ee }}$ s equation [24] and the average crystallite size is was approximately $36 \mathrm{~nm}$.



Fig. 1. Observed PXRD profile of $\mathrm{TiO}_{2}$ materials

The observed PXRD data sets of rutile phase $\mathrm{TiO}_{2}$ were refined using Rietveld profile refinement technique using JANA2006 software [25]. The initial parameter was taken from rutile $\mathrm{TiO}_{2}$ as $\mathrm{P} 42 / \mathrm{mnm}$ space group of and $\mathrm{Ti}$ at $2 \mathrm{a}$ Wyckoff positions $(0,0,0)$ and $\mathrm{O}$ at $4 \mathrm{f}$ Wyckoff coordinates
$(0.3053,0.3053,0)$, respectively [26]. The well indexed refined profile of rutile phase $\mathrm{TiO}_{2}$ was shown in Fig. 2. The refined structural parameters of rutile $\mathrm{TiO}_{2}$ were listed in table 1 .

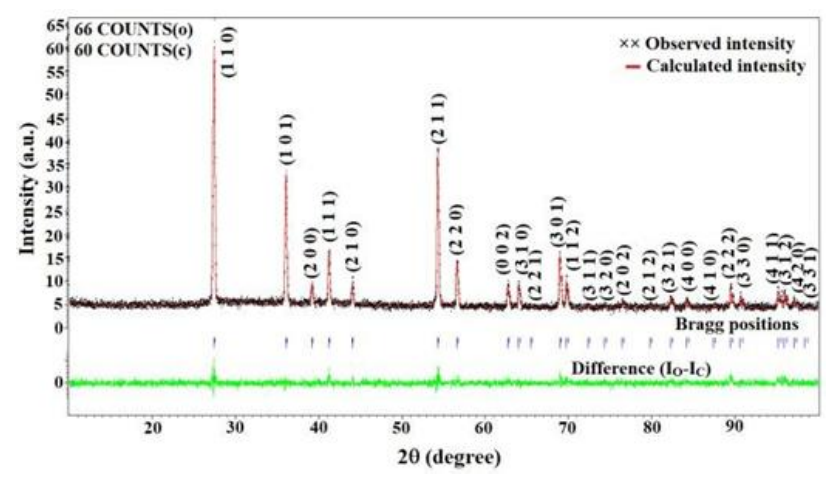

Fig. 2. Refined profile of rutile $\mathrm{TiO}_{2}$ sintered at $1000^{\circ} \mathrm{C}$

Table-I: Refined parameters of $\mathrm{TiO}_{2}$

\begin{tabular}{|c|c|}
\hline PARAMETERS & TIO $_{\mathbf{2}}$ \\
\hline $\mathrm{a}=\mathrm{b}(\AA)$ & $4.5929(4)$ \\
\hline $\mathrm{c}(\AA)$ & $2.9586(2)$ \\
\hline Volume $(\AA)$ & $62.39(1)$ \\
\hline Density $\left(\mathrm{g} / \mathrm{cm}^{3}\right)$ & 4.25 \\
\hline $\mathrm{R}_{\text {obs }}(\%)$ & 2.13 \\
\hline $\mathrm{R}_{\mathrm{p}}(\%)$ & 6.34 \\
\hline $\mathrm{F}^{(000)}$ & 76 \\
\hline $\mathrm{GOF}^{\mathrm{d}}$ & 0.19 \\
\hline
\end{tabular}

$\mathrm{R}_{\mathrm{obs}}$ - observed profile reliability factor.

$\mathrm{R}_{\mathrm{P}}$ - profile reliability factor.

$\mathrm{F}_{(000)}$ - Total number of electrons per unit cell.

GOF - Goodness of Fit.

\section{B. SEM analysis}

The morphology of the commercial $\mathrm{TiO}_{2}$ and sintered $\mathrm{TiO}_{2}$ materials were examined by scanning electron microscopy (SEM) and shown in Fig. 3. From the Fig. 3, highly agglomerated and uncleared morphology was observed for the commercial $\mathrm{TiO}_{2}$ and $\mathrm{TiO}_{2}$ sintered at $800^{\circ} \mathrm{C}$. On contrary, $\mathrm{TiO}_{2}$ sintered at $1000^{\circ} \mathrm{C}$ clearly showed Fig. 3. SEM images of $\mathrm{TiO}_{2}$ materials well defined plate like morphology. The average particle size of rutile $\mathrm{TiO}_{2}$ was at approximately $\sim 200 \mathrm{~nm}$. The change in the morphology of Rutile $\mathrm{TiO}_{2}$ confirmed the transformation of anatase phase to highly crystalline rutile phase of $\mathrm{TiO}_{2}$.
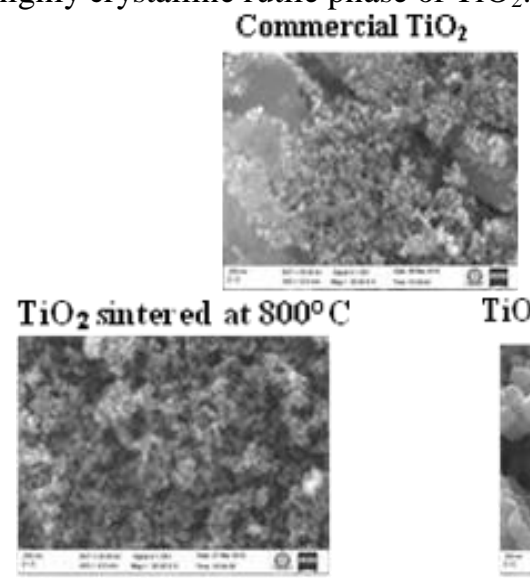

$\mathrm{TiO}_{2}$ sinter ed at $1000^{\circ} \mathrm{C}$

Fig. 3. SEM images of $\mathrm{TiO} 2$ materials 


\section{Energy Dispersive Spectroscopy (EDS)}

The EDS spectrum of commercial $\mathrm{TiO}_{2}$ and sintered $\mathrm{TiO}_{2}$ materials was shown in Fig. 4. EDS spectrum of commercial $\mathrm{TiO}_{2}$ showed that the low intensity titanium peak which may be influenced by the mixed anatase and rutile phases. But for sintered sample at $800^{\circ} \mathrm{C}$ and $1000^{\circ} \mathrm{C}$, the intensity of titanium was gradually increased. The EDS spectra showed higher intensity for single phased $\mathrm{TiO}_{2}$ sintered at $1000^{\circ} \mathrm{C}$, which may due to lattice rearrangement in the samples. Commercial $\mathrm{TiO}_{2}$

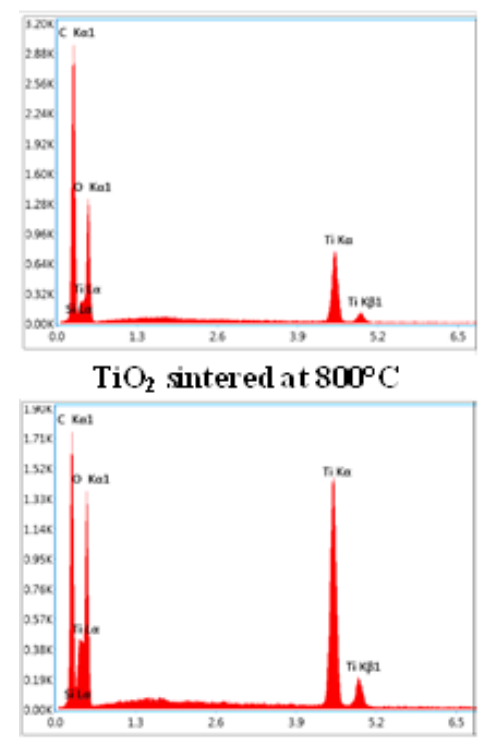

$\mathrm{TiO}_{2}$ sintered at $1000^{\circ} \mathrm{C}$

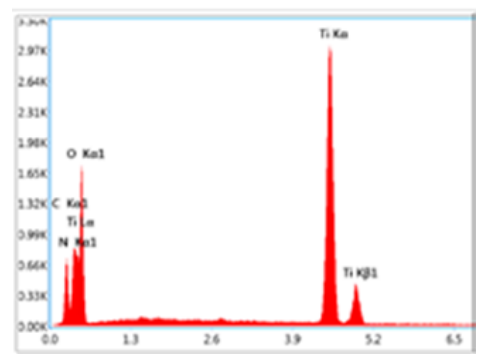

Fig. 4. EDS spectrum of $\mathrm{TiO} 2$ materials

\section{Photoluminescence (PL) property analysis}

The photoluminescence behavior of commercial $\mathrm{TiO}_{2}$ and sintered $\mathrm{TiO}_{2}$ materials were analyzed by photoluminescence (PL) spectroscopy. Fig. 5 showed the excitation and emission spectra of $\mathrm{TiO}_{2}$ materials. The excitation wavelength obtained at around $427 \mathrm{~nm}$ and emission wavelength displayed at $470 \mathrm{~nm}$ at blue wavelength was clearly seen in Fig. 5. The intensity of both excitation and emission spectra gradually increased and reached the maximum intensity for single phased rutile $\mathrm{TiO}_{2}$. This may be due to the sintering temperature which improved the surface states by enhancing the number of surface defects and improved the crystallinity of $\mathrm{TiO}_{2}$ samples [27]. In Fig. 5, the emission spectra obtained in blue region at $470 \mathrm{~nm}$, was attributed by band to band transition. Self-trapped excitons (STE), oxygen vacancies and surface states are three kinds of physical origins responsible for the band to band transition in crystal lattice $[28,29]$. In this study, the rutile $\mathrm{TiO}_{2}$ emission appearing at $470 \mathrm{~nm}$ was as a result of emission from lower levels in $\mathrm{Ti}^{3+}$
$3 \mathrm{~d}$ states of $\mathrm{TiO}_{2}$ lattice to deep levels (acceptor) created by -OH orbital [30].

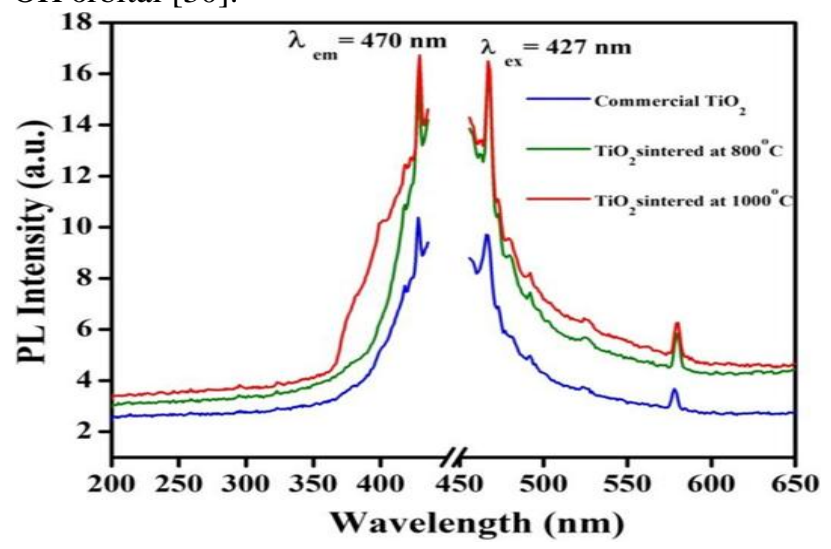

Fig. 5. PL behavior of $\mathrm{TiO}_{2}$ materials

\section{E. Charge density analysis}

The structure factors which were obtained from the Rietveld method were taken as to evaluate the electron density distribution analysis of the $\mathrm{TiO}_{2}$ materials. The maximum entropy method (MEM) [23] is a versatile method and standard tool to analyze the charge density distributions in the unit cell employed by the DYSNOMIA software [31]. In the present report, the charge density distributions in the unit cell were constructed for commercial and sintered $\mathrm{TiO}_{2}$ samples. Three-dimensional, two-dimensional and one-dimensional charge density views can be visualized by VESTA software [32].

Fig. 6 showed the three-dimensional electron density distribution of rutile phase $\mathrm{TiO}_{2}$. The spherical core of Ti and $\mathrm{O}$ atoms can be seen in Fig. 6. The shaded yellow region was represented by electron cloud using iso-surface level of 0.55 $\mathrm{e} / \AA^{3}$. The Rutile unit cell contained two different Ti-O bonds which are clearly shown in Fig. 6 (a). Figs. 7 (a) and (b) showed the two-dimensional charge density distributions drawn on (100) and (110) lattice planes covering the contour lines between $0-2 \mathrm{e} / \AA^{3}$ with the interval of $0.2 \mathrm{e} / \AA^{3}$. The exact bond length and electron density distribution at the Mid-point of the bond of single phase $\mathrm{TiO}_{2}$ were determined by one dimensional charge density profile and the profiles are presented in Figs. 8 \& 9.

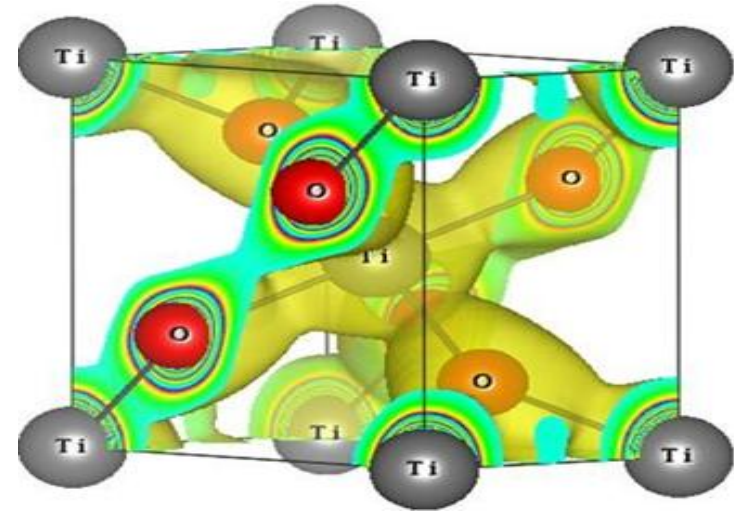

Fig. 6. 3-D unit cell of rutile $\mathrm{TiO}_{2}$ 


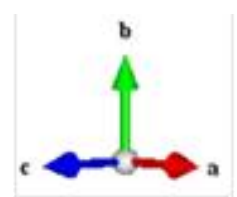

$x, y$ and $z$ direction

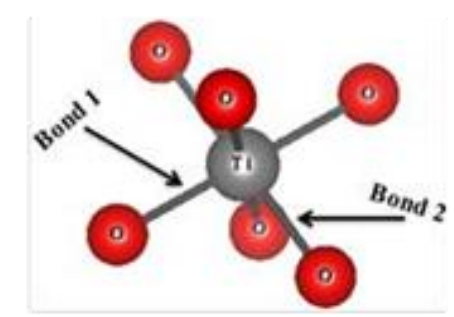

Fig. 7. (a) Bonding representation of Ti and $\mathrm{O}$

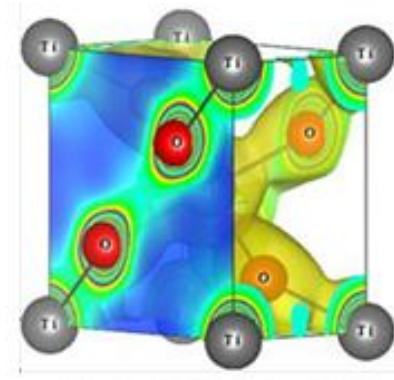

3-D wut cell: (100) plane shaded

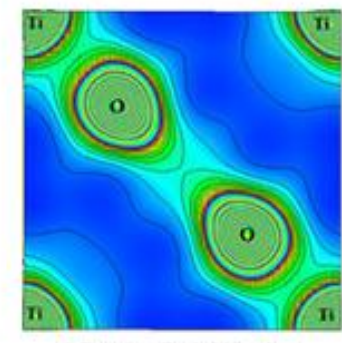

2-D uait cell of (100) plane
Fig. 8. (a) 2D map of rutile TiO2 on (100) miller plane

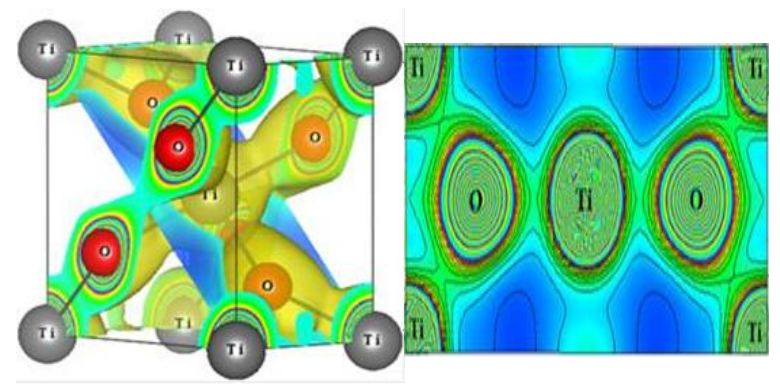

3-D unit cell; (110) plane shaded

2.D unit cell of (l10) plane

Fig. 9. (b) 2-D map of rutile $\mathrm{TiO}_{2}$ on (110) miller plane

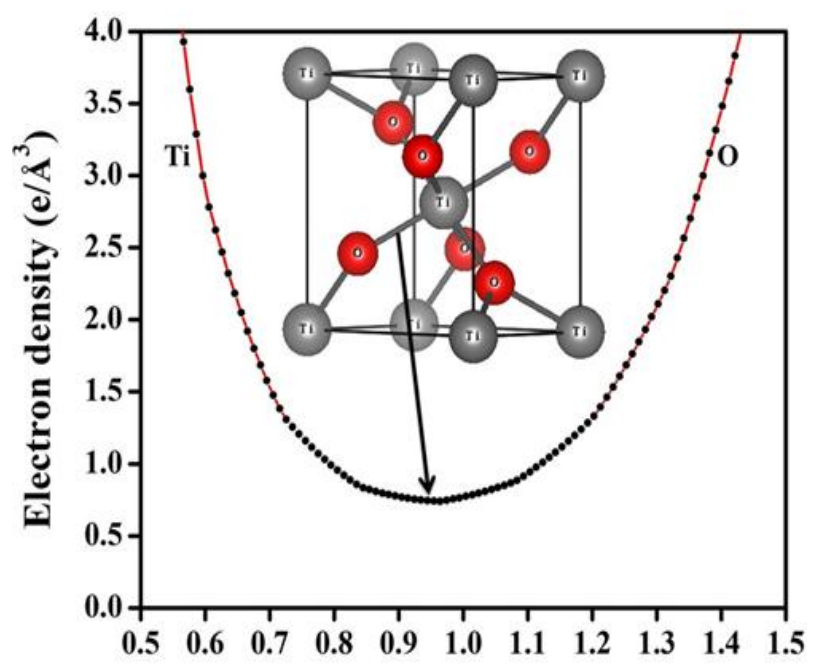

Distance along Ti-O bond $(\AA)$

Fig. 10. 1-D profile of Ti-O (bond 1)

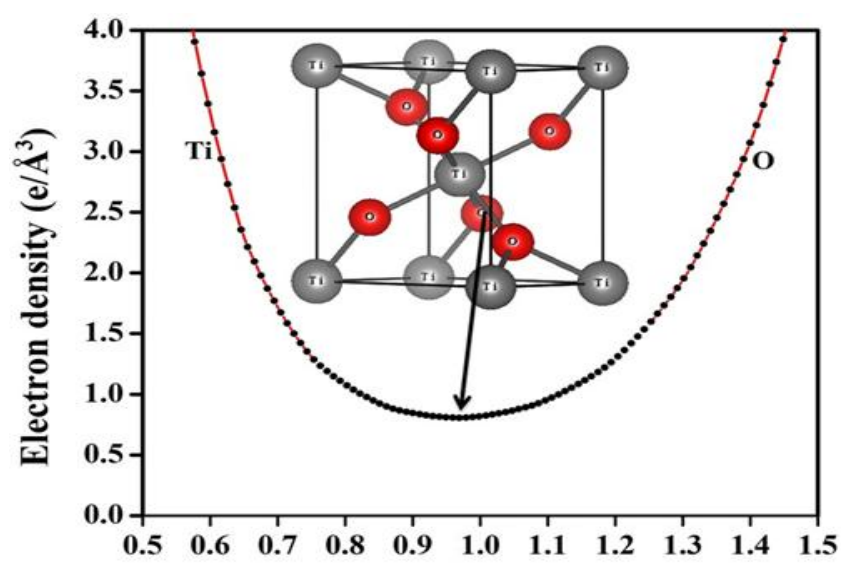

Distance along Ti-O bond $(\AA)$

Fig. 11. 1-D profile of Ti-O (bond 2)

Table-III: Electron density distributions of $\mathrm{TiO}_{2}$

\begin{tabular}{|c|c|c|c|}
\hline Bond & $\begin{array}{c}\text { Bond length } \\
(\AA)\end{array}$ & $\begin{array}{c}\text { Bond Critical } \\
\text { Point }(\AA)\end{array}$ & $\begin{array}{c}\text { Mid-bond electron } \\
\text { density }\left(\mathbf{e} / \AA^{\mathbf{3}}\right)\end{array}$ \\
\hline Ti-O & 1.9780 & 0.9641 & 0.7403 \\
\hline Ti-O & 1.9477 & 0.9689 & 0.8053 \\
\hline
\end{tabular}

\section{CONCLUSION}

In conclusion, the single rutile phase $\mathrm{TiO}_{2}$ was obtained from commercial $\mathrm{TiO}_{2}$ having mixed phase of crystal structure when it was sintered at $1000^{\circ} \mathrm{C}$. The sintered $\mathrm{TiO}_{2}$ material was characterized by various analytical and spectroscopic techniques. PXRD analysis confirmed the Rutile phase $\mathrm{TiO}_{2}$. The plate like morphology was obtained for rutile phase $\mathrm{TiO}_{2}$ which was affirmed by SEM images. Element conformation of $\mathrm{Ti}$ and $\mathrm{O}$ atoms were identified by EDS analysis. The covalent nature of Ti-O chemical bonds

\section{ACKNOWLEDGMENT}

One of author D.S gratefully acknowledges Kalasalingam Academy of Research and Education (KARE) "Deemed to be University" for providing University Research Fellowship (URF). Authors acknowledge International Research Centre (IRC), KARE for supporting instrumentation facilities. The author thank to Dr. AR. Lakshmanan, Dean of (R\&D), Saveetha Engineering College for PL measurements.

\section{REFERENCES}

1. F. Zaera, "Nanostructured materials for applications in heterogeneous catalysis," Chem. Soc. Rev., vol. 42, no. 7, pp. 2746-2762, 2013.

2. J. Jeevanandam, A. Barhoum, Y. S. Chan, A. Dufresne, and M. K. Danquah, "Review on nanoparticles and nanostructured materials: History, sources, toxicity and regulations,” Beilstein J. Nanotechnol., vol. 9, no. 1, pp. 1050-1074, 2018.

3. K. Nakata and A. Fujishima, "TiO2 photocatalysis: Design and applications," J. Photochem. Photobiol. C Photochem. Rev., vol. 13, no. 3, pp. 169-189, 2012.

4. D. Ph, "Dynamic Behavior of Piping Systems Under Transient Flow Conditions," vol. 2014, 2014.

5. J. Bai and B. Zhou, "Titanium Dioxide Nanomaterials for Sensor Applications,” Chem. Rev., vol. 114, no. 19, pp. 10131-10176, 2014.

6. Z. Weng, H. Guo, X. Liu, S. Wu, K. W. K. Yeung, and P. K. Chu, "Nanostructured $\mathrm{TiO}<\inf >2</ \mathrm{inf}>$ for energy conversion and storage," RSC Adv., vol. 3, no. 47, pp. 24758-24775, 2013. 
7. M. Chung and W. Liu, "TiO 2 Nanostructured Films synthesis by Hydrothermal Process,” pp. 669-672.

8. V. R. Akshay, B. Arun, G. Mandal, and M. Vasundhara, "Structural, optical and magnetic behavior of sol-gel derived Ni-doped dilute magnetic semiconductor TiO 2 nanocrystals for advanced functional applications," Phys. Chem. Chem. Phys., vol. 21, no. 5, pp. 2519-2532, 2019.

9. M. K. Nowotny, T. Bak, and J. Nowotny, "Electrical properties and defect chemistry of TiO2 single crystal. I. Electrical conductivity," J. Phys. Chem. B, vol. 110, no. 33, pp. 16270-16282, 2006.

10. N. Rahimi, R. A. Pax, and E. M. A. Gray, "Review of functional titanium oxides. I: TiO2and its modifications," Prog. Solid State Chem., vol. 44, no. 3, pp. 86-105, 2016.

11. Q. Zhang, C. Sun, J. Yan, X. Hu, S. Zhou, and P. Chen, "Perpendicular rutile nanosheets on anatase nanofibers: Heterostructured $\mathrm{TiO} 2$ nanocomposites via a mild solvothermal method," Solid State Sci., vol. 12, no. 7, pp. 1274-1277, 2010.

12. C. A. Betty, N. Bhosale, and P. S. Patil, "CrystEngComm Hydrotherma synthesis of rutile $\mathrm{TiO} 2$ with hierarchical microspheres and their characterization," pp. 6349-6351, 2011.

13. W. Xue-wei and L. Xiao-, "Phase study of titanium dioxide nanoparticle prepared via sol-gel process Phase study of titanium dioxide nanoparticle prepared via sol- gel process," 2018.

14. A. Ibrahim, W. Mekprasart, and W. Pecharapa, "ScienceDirect Anatase / Rutile TiO 2 composite prepared via sonochemical process and their photocatalytic activity," Mater. Today Proc., vol. 4, no. 5, pp. 6159-6165, 2017.

15. Y. Chen, M. Marsh, J. S. Williams, and B. Ninham, "Production of rutile from ilmenite by room temperature ball-milling-induced sulphurisation reaction."

16. V. G. Bessergenev, I. V Khmelinskii, R. J. F. Pereira, and V. V Krisuk, "Preparation of $\mathrm{TiO}_{2}$ films by CVD method and its electrical structural and optical properties," vol. 64, pp. 275-279, 2002.

17. K. Ri, L. R. Lgh, Y. L. Q. O. Uurolgrqh, D. Dv, D. J. Dqg, and K. Dwlrq, "\$ 6lpsoh \&khplfdo 3uhflslwdwlrq 0hwkrg ri 7lwdqlxp "lr[lgh 1 dqrsduwlfohv 8vlqj 3rolylqlo 3luurolgrqh dv d \&dsslqj \$jhqw dqg 7khlu \&kdudfwhul]dwlrq," vol. 10, no. 5, pp. 556-559, 2016

18. R. Tio et al., "Hydrogen Impurity Defects in," pp. 1-7, 2015.

19. D. A. H. Hanaor and C. C. Sorrell, "Review of the anatase to rutile phase transformation," pp. 855-874, 2011

20. W. Wang, B. Gu, L. Liang, W. A. Hamilton, and D. J. Wesolowski, "Low-Temperature Hydrolysis : Effects of Solvent Composition," vol. 108 , no. 39 , pp. $2-5,2004$

21. D. A. H. Hanaor and C. C. Sorrell, "Review of the anatase to rutile phase transformation," J. Mater. Sci., vol. 46, no. 4, pp. 855-874, 2011.

22. S. Sintering and D. L. Johnson, "Solid-State Sintering," pp. 173-183, 1970.

23. S. B. H. Gmbh, The maximum Enthropy Method. 2001

24. A.L. Patterson, The Scherrer Formula for I-Ray Particle Size Determination. Phys. Rev., 6, pp.978-982 (1939).

25. V. Petricek, M. Dusek, L. Palatinus, Jana2006. The crystallographic computing system, Institute of Physics, Praha, Czech Republic, (2006)

26. P. Mohanty, S. Saravanakumar, R. Saravanan, and C. Rath, "TiO Nanowires Grown from Nanoparticles: Structure and Charge Density Study," 2013.

27. L. Chetibi and T. Busko, "Photoluminescence properties of $\mathrm{TiO} 2$ nanofibers," 2017.

28. S. Mochizuki, "Intense white luminescence of $\mathrm{Sm} 2 \mathrm{O} 3$ irradiated with ultraviolet laser light under vacuum," vol. 342, pp. 944-948, 2003.

29. V. P. Tolstoy and B. Altangerel, "A new ,, fluoride " synthesis route for successive ionic layer deposition of the $\mathrm{Zn} \times \mathrm{Zr}(\mathrm{OH})$ y $\mathrm{F} \mathrm{z} \cdot \mathrm{nH} 2 \mathrm{O}$ nanolayers," vol. 61, pp. 123-125, 2007.

30. S. Mathew, A. K. Prasad, T. Benoy, P. P. Rakesh, M. Hari, and T. M. Libish, "UV-Visible Photoluminescence of TiO 2 Nanoparticles Prepared by Hydrothermal Method," 2012.

31. K. Momma, T. Ikeda, A.A. Belik, F. Izumi, Dysnomia, A computer program for maximum-entropy method (MEM) analysis and its performance in the MEM-based pattern fitting, pp.1-10, (2013).

32. K. Momma, F. Izumi, VESTA 3 for three-dimensional visualization of crystal, volumetric and morphology data, pp.1272-1276 (2011).

\section{AUTHORS PROFILE}

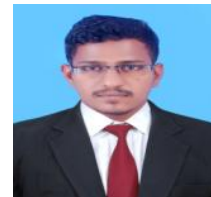

D. Sivaganesh is a $\mathrm{Ph} . \mathrm{D}$ student at Kalasalingam University, India. His research interest is structural and photoluminescence properties of phosphor materials

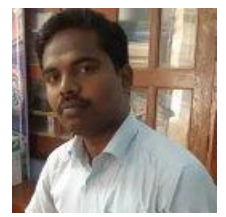

S. Saravanakumar is working as an assistant professor at Kalasalingam University and he received his Ph.D. degree in 2015 at Madurai Kamaraj University, India. His main research interest is materials science. He has published 26 articles in journals with over 107 citations.

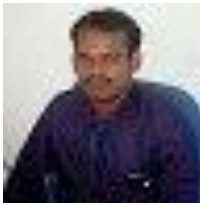

V. Sivakumar received his Ph.D. degree in 2015 at Anna University, India. With a research interest in silicate phosphor materials for LED and display application

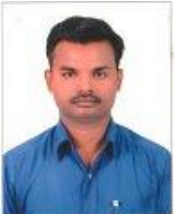

S. Sasikumar received his Ph.D degree in 2018 at Madurai Kamaraj University, India. His research interest is the applications of piezo - electric materials. He has published 19 research articles in reputed journal with 56 citations

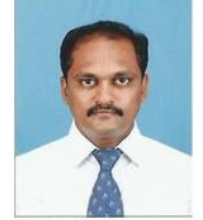

Dr. Rajajeyagantha Ramanathan completed his B.Sc., Applied Sciences from Coimbatore Institute of Technology, Coimbatore and M.Sc., Applied Chemsitry from National Institute of Technology, Tiruchirappalli. He was awarded "Best Outgoing Student" with a gold medal in M.Sc. He completed his $\mathrm{Ph} . \mathrm{D}$ (Surface Science) under TWAS-CNPq fellowhip from Federal University of Rio Grande do Sul, RS 